This item was submitted to Loughborough's Research Repository by the author.

Items in Figshare are protected by copyright, with all rights reserved, unless otherwise indicated.

\title{
An empirical study of the complexity of requirements management in construction projects
}

\section{PLEASE CITE THE PUBLISHED VERSION}

http://dx.doi.org/10.1108/ECAM-09-2013-0084

\section{PUBLISHER}

(C) Emerald Group Publishing Limited

\section{VERSION}

AM (Accepted Manuscript)

\section{PUBLISHER STATEMENT}

This work is made available according to the conditions of the Creative Commons Attribution-NonCommercialNoDerivatives 4.0 International (CC BY-NC-ND 4.0) licence. Full details of this licence are available at: https://creativecommons.org/licenses/by-nc-nd/4.0/

\section{LICENCE}

CC BY-NC-ND 4.0

\section{REPOSITORY RECORD}

Jallow, Abdou Karim, Peter Demian, Andrew N. Baldwin, and Chimay J. Anumba. 2014. "An Empirical Study of the Complexity of Requirements Management in Construction Projects". Loughborough University. https://hdl.handle.net/2134/16172. 


\title{
An Empirical Study of the Complexity of Requirements Management in Construction Projects
}

\author{
Abdou Karim Jallow \\ Supply Chain and Information Systems, Smeal College of Business, \\ The Pennsylvania State University, University Park, Pennsylvania, USA \\ Peter Demian and Andrew N. Baldwin \\ School of Civil and Building Engineering, Loughborough University, \\ Loughborough, UK, and \\ Chimay Anumba \\ Department of Architectural Engineering, The Pennsylvania State University, \\ University Park, Pennsylvania, USA
}

\begin{abstract}
Purpose -The aim of this paper was to investigate in-depth the current approach of managing client requirements in construction and to highlight the significant factors, which contribute to the complexity of managing the requirements in order to define a better approach.

Design/methodology/approach - A case study of a leading international global built asset and engineering consultancy organization was conducted over two years. The case study was conducted principally using semi-participant observations supplemented with other qualitative data collection methods (i.e., interviews, questionnaires and document analysis). Thematic analysis was used to analyse the data.
\end{abstract}

Findings - The results highlight major factors associated with the complexity of managing client requirements information, which include: mechanisms for documentation, storage and access, distribution of requirements information between stakeholders and across lifecycle phases of a project, traceability management and the provision of effective change management incorporating dependency checking and impact analysis.

Research limitations/implications - The main limitation of the research is the use of an in-depth study of a single organization, which applied the same project management method across all the projects they managed. Further work is planned to develop the proposed framework fully, and develop a software prototype to operationalize and evaluate its industrial applicability with construction projects.

Practical implications - The implications of this research is that a better approach to managing requirements information is needed, which will facilitate the design, construction and operations of buildings within budget and time. An integrated framework and an associated tool are suggested to implement the approach.

Originality/value - This study identifies major research gaps and problems in the AEC/FM industry; proposes and presents eRIM framework to facilitate lifecycle management of the requirements.

\section{Keywords:}

Construction project, Information management, Client requirements, Requirements management

Article Classification: Research paper 
AK Jallow , P Demian , AN Baldwin , C Anumba , (2014) "An empirical study of the complexity of requirements management in construction projects", Engineering, Construction and Architectural Management, 21( )5, 505 - 531

\section{Introduction}

The Architecture, Engineering, Construction and Facilities Management (AEC/FM) Industry is one of the largest and most diverse commercial engineering industries. It develops its projects and services through integrated project teams and professionals who may be dispersed over several geographical locations and organizations (Anumba et al., 2002; Griffith, 2011). The construction process is known to be information intensive with large amounts of information such as drawings, specifications, bills of quantities generated mostly in paper-based form, which are complex to manage (Sun and Howard, 2004). History has shown that construction projects are frequently late, over budget and suffer from poor workmanship and materials problems (Vasilescu et al., 2009). This often results in conflict and litigation. Many factors are associated as causes of this problem, with a reoccurring theme being poor management of brief/program or requirements management (Davis and Zweig, 2000; Fernie et al., 2003). The industry's fragmented nature of project development and lack of integration have also been reported to be the causes of several problems and difficulties, especially with project delivery systems (Bouchlaghem et al., 2004; Latham, 1994; Egan, 1998). The geographically distributed teams and the different heterogeneous systems used make the much needed effective information communication difficult to achieve (Anumba et al., 2002). A typical construction project lifecycle comprises different phases incorporating various stakeholders. Amongst these stakeholders is the client who states the purpose of the project and the needs and expectations to be delivered or achieved at the end of a project. These statements become the client requirements of the project, the foundation for design, construction and use/operations. Information about client requirements needs to be managed across the entire life cycle phases and between all stakeholders (e.g. between clients and designers). However, several challenges exist causing inefficiencies in managing the client requirements. The lack of a common language is a major problem that hinders the communication of requirements information between stakeholders (Austin et al., 2002). The original brief, which holds the clients requirements is not carried along throughout the project phases, and often not updated to reflect changing needs (Kiviniemi et al., 2004). The requirements information is not widely distributed and accessed by all team members and stakeholders.

Consequently, there is the need to address the complexities associated with these problems. This study identifies major research gaps and problems in the AEC/FM industry, which requires attention as follows: (i) lack of a defined approach to effectively manage client requirements information collaboratively through the building lifecycle; (ii) lack of a repository of requirements in an information management system; (iii) ineffective coordination and control of the requirements change management process including sufficient capture of change history and lessons learned; (iv) no known formal, structured and standardized method and processes exists for managing changes and dependencies between requirements 
and for assessing impacts and (v) lack of integration and interoperability of systems used for the management of requirements information, in particular between requirement repository (if it exists) and change management systems. Little research has focused on identifying the complexities associated with the inefficiencies of integrated lifecycle requirements management in construction in order to define a better approach.

The purpose of the broader research is to develop an integrated framework for managing client requirements information. The aim of this paper is to investigate in-depth the current approach of managing client requirements in construction and to highlight the significant factors, which contribute to the complexity of managing the requirements. It is an extension of earlier work by Jallow et al (2008) and Jallow (2010), which initially investigated lifecycle requirements management in construction and proposed an initial framework for a better approach. The objectives of the paper are: (i) to provide a review of current practice of managing client requirements in construction projects; (ii) identify inefficiency and ineffectiveness in existing methods and (iii) propose an integrated framework to facilitate integrated lifecycle management of the requirements. This will help formulate a better approach to facilitate the design, construction and service delivery of construction projects within budget and time; and realizing high quality of built facilities and stakeholder benefits. The scope of the research is the investigation of client requirements management in construction, centered on public institution buildings. Requirements management in this research focuses on the activities dealing with the requirements once they have been elicited. These are: the mechanisms for requirements documentation and storage, access and retrieval, distribution, managing changes, traceability and dependency checking (to facilitate impact analysis), and communication as the basis of requirements management.

\section{Related Work}

\subsection{Construction Project Management}

History has shown that large and complex projects typically suffer from a lack of good project management practice. This results in project failures. In almost every industry, this problem has been reported. The Chartered Institute of Building (CIOB) (2011) recognizes that delayed completion affects all industries in all countries ranging from oil and gas, civil engineering, IT, process plant, shipbuilding and marine work contracts; and the bigger the project, the more damage delayed completion causes to costs. According to Mahaney and Lederer (2010) and Tesch et al. (2007), too many projects exceed their initial budgets; some are completed beyond their target dates, whilst some lack the expected quality or performance requirements. In some cases, projects are cancelled before completion. 
In the construction industry, projects are only occasionally abandoned once commenced. However, many mega infrastructure projects fail to meet client's requirements. Some get completed on schedule and on budget but fail to meet the needs of users. An example is Heathrow Terminal 5, one of Europe's largest and most complex construction projects (Potts, 2008) which, on its opening day, faced multiple problems resulting in the cancellation of flights and loss of passenger luggage (Brady and Davies, 2010). Analysis of the Terminal 5 project indicates that inadequate client requirements management contributed to the problem. Project management processes implemented to deliver such projects therefore have to incorporate innovative approaches to managing the different aspects of the project through all its life phases. Several issues are reported to cause project failures which include lack of stakeholder involvement, inadequate management of client/customer and user requirements, incompetent development team, lack of effective risk management and planning and monitoring structures amongst others. For a project to be deemed successful, it has to be completed within the defined constraints (budget and time) and meet the quality and performance requirements. This is a challenging task, thus, efficient project management must be applied in a manner that adequate management procedures are put in place to transform client requirements into finish products. The functions of construction project management include: defining client's requirements; establishing a good communications channels in which all parties can perform effectively; developing and managing a change control procedures; and monitoring all decisions and approval in respect of the programme (Royal Institute of British Architects RIBA, 2007). Project failure has been common over the past few years and amongst the notable common causes of failure is the lack of adequate, robust and effective project team integration between clients, the supplier team and the supply chain (Office of Government Commerce, 2005). According to Gallaher et al. (2004), a large number of contractors and subcontractors are often involved in large construction projects all sharing information and designs; huge delay cost can be caused in finding documents. Another major factor is the complex nature of collaboration in construction projects and the user groups especially in projects where different users have individual requirements for a building. This requires coordinated and planned structures to support requirements information management. Collaborative working is thus a fundamental quality of requirements information management. Currently, there is little support for distributing and congregating the activities of the management process amongst the people who are involved in it. Management of the requirements information is important for visibility, tracking and traceability of client needs which are crucial for the management of changes. It can also facilitate better requirements information exchange, collaboration and concurrent processes in an extended dynamic enterprise. However, Fernie et al., (2003) indicate that few documented methods exist that provide traceability and ability to analyze change throughout the life of projects. 
AK Jallow , P Demian , AN Baldwin , C Anumba , (2014) "An empirical study of the complexity of requirements management in construction projects", Engineering, Construction and Architectural Management, 21( )5, 505 - 531

\subsection{Client Requirements - brief overview}

From a construction industry point-of-view, Kamara and Anumba (2000) state that objectives, needs, wishes and expectations of the client are described as client requirements. Kamara, Anumba and Evbuomwan (2002) further note that client requirements, often termed as the 'voice of the client', include the collective wishes and expectations of the various components of the client body. The requirements as target information describe the facility that will satisfy the client's objectives (or business needs). According to the Office of Government Commerce (2009b), common to all development and other engineering activities, requirements are capabilities and objectives to which any product or service must conform. Requirements may also be regarded as measurable statements of the client's needs which are transformed into an architectural design and subsequently into a finished facility. They can be used to assess the completed facility.

\subsection{Briefing}

Briefing (i.e., programming in USA) is one of the earliest phases of any construction project. This includes client requirements elicitation, analysis, specification and validation. It is a process to gather and determine client needs, wishes and expectations for a building leading to statements of architectural problem and the requirements to be met (Pena and Parshall, 2001). The briefing process involves understanding the client's needs and articulating them in a way that will make sure the vision of the project is compatible with the resulting product - e.g., building (Austin et al., 2002). The outcome of the briefing process is a brief, a document detailing the information about client requirements. This information is a vital resource needed at each project phase: design, construction and through-life of a facility. Traditionally, the brief has remained an unaltered statement of intent. However, the current trend is to look at briefing as an integrated part of the entire construction and project management processes and not just as part of an early stage (Worthington, 2000). This is important because client requirements often change dramatically over a facility's life. This evolution needs to be understood as, for example, if the facility is to be refurbished or adapted for uses other than those for which it was originally designed, it is necessary to review all the client requirements. The RIBA plan of work specifies five main stages of a project lifecycle. These are: Preparation, Design, Pre-construction, Construction and Use. These phases are subdivided into work stages A - L (without a stage I) (RIBA, 2007). However, the lettered A-J stages are being replaced by a 7-numbered work stages (i.e., 1 - 7 - Preparation, Concept design, Developed design, Technical design, Specialist design, Construction and Use \& Aftercare) according to RIBA plan of work 2013 (RIBA, 2012). The initial client requirements are generated and developed in the 'preparation' phase. Several people and roles are involved in this process, including client (or all client interests), architect/designer depending on type of procurement for the development of the initial brief. 
AK Jallow , P Demian , AN Baldwin , C Anumba , (2014) "An empirical study of the complexity of requirements management in construction projects", Engineering, Construction and Architectural Management, 21( )5, 505 - 531

However, requirements vary in precision and detail, and granularity of the requirements information changes as projects progress, therefore, this recognition is relevant to indicate the characteristic of that variation, the project phases and the different roles involved in the process. During the development of the strategic brief, more roles get involve including the engineers, QS, client/client representatives. Each of the parties has specific role in the requirements development and entire construction. Despite the different teams involved in a project, recent developments in construction management, in particular the building information modeling (BIM) BIM requires integrated teams working collaboratively to replace the traditional fragmentation of projects teams (Sinclair, 2012). The degree of control the client and/or the project teams (e.g., architect or contractor) have depends on the type of project procurement. In understanding the types of roles and their level of control given a problem, three types of consultant roles are proposed by Edgar Schein, namely: purchase-of-expertise model, doctor-patient model and process consultation model (Rockwood, 1993). According to Schein (1978), the first two models are expert and content oriented where focus is on the task to be performed or the problem to be solved. In the purchaseof-expertise model, a client knows exactly what the problem is; what needs to be done and who to get help from. The client then hires the consultant for help but not to get involved in the process of consultation itself. In the doctor-patient model, the client knows something is wrong but does not know how to figure out what exactly is wrong, and how to fix it. The client becomes totally dependent on a consultant who is hired to diagnose the problem, and does not take part until such a time that he/she is contacted to become active in the process. The process consultative model is 'process' oriented focusing on the way the problem is confronted, defined, worked on, and eventually solved. In this model, the consultant (either as a catalyst or facilitator), does not take total control of the problem, but the client is involved in the diagnoses of the problem and generating a solution. However, in trying to solve any particular problem, a consultant inevitably may end up utilizing all three models at different times or with different clients (Schein, 1978). Learning from these types of consultant roles, the client's brief, which documents the requirements (including functional requirements of the building; project goals with desired outcomes; operation data and post occupancy requirements), and the requirements management process would also depend on the management of the roles and relationships of the various parties.

The relevance and importance of managing client requirements is to facilitate the successful completion of projects; ensuring the benefits envisaged at the start of the project are realized at the completion and all the way through the life of the facility. Benefits are measurable quantification of improvements as an outcome of change perceived as positive to stakeholders (Office of Government Commerce, 2009a; Bradley, 2010). Benefits often are not realized until a project is completed, thus it is relevant that benefits realization management as a method, supports organizations in the identification and management of 
benefits through the whole lifecycle of programmes and projects (Sapountzis et al., 2009). Similarly, value (i.e., the benefits to the client), which is described as the relationship between the satisfaction of needs and the resources used in achieving that satisfaction (British Standards Institution, 2000) needs to be managed. Value management, a project management technique provides a structured approach to the assessment and development of a project to satisfy or exceed the requirements of the various stakeholders and increase the likelihood of achieving the benefits (Kliniotou, 2004). It has been highlighted that benefits realization management is closely associated with value management (Breese, 2012); similarly, requirements management is also crucial for value management and benefits realization of projects (Jallow, 2011). Green et al. (2004) believe that requirements management has no equivalent in construction but similar practices are applied such as programming, value management and change control.

\subsection{Requirements Management}

Requirements need to be managed throughout the project development lifecycle. This process is referred to as requirements management (RM). Its definition has been adapted by many experts and tends to follow its applicability within particular industry. However, no matter in which industry it is being applied, it is an indispensable feature of every product development endeavor. Aouad and Arayici (2010) indicate that Requirements Engineering (RE) is concerned with the real world problems to be addressed by a software system and is focused on the elicitation, analysis, specification and validation of software requirements; requirements management is a generic activity of RE. The Office of Government Commerce (2009b) recognizes the process of elicitation, documentation, organization, and tracking requirements information and communicating across the various stakeholders and project teams as RM. However, with many stakeholders involved and interested in requirements, its dissemination must be considered in the process of managing the requirements information. Testing the requirements is important to ascertain that they are valid and accurate to achieve the purpose for which they were created. Requirements are open to changes and their documentation should enable such changes to be evaluated and implemented. This means that management of requirements is crucial in understanding the impact of changes by performing impact analysis (Brennan, 2009). Changes to requirements often go through an approval process. Once the changes are approved, the original requirements document (i.e., the baseline version) should be maintained and updated with the changes (Brennan, 2009). As such, a variable that discusses modification has been added in the definition by Nuseibeh and Easterbrook (2000) who state that RM involves the process of identifying stakeholders and their needs, which should be documented in a form that is amendable to evaluation, communication and subsequent implementation. Requirements management presents significant difficulties when stakeholders are distributed, as in today's global 
projects and is identified as one of the most collaboration-intensive activities in software development (Sinha, Sengupta and Chandra, 2006). In product development through the extended enterprise, Roy et al. (2005) recognize the necessity to formalize and automate the requirements management process which is manual and time consuming in order to reduce the product development time and cost. Halbleib (2004) indicates that managing requirements is not an event but a process which starts at the outset of a project and continues until the developed system has been discontinued and is no longer supported. Wiegers and McKinsey (2005) indicate that developing and managing requirements is hard, and it is about dealing with the requirements once they are in place. Green et al. (2004) argue that requirements management has to be based on a process even where a tool is available. Poor management of requirements has been attributed to failures of several projects. The inability to map the requirements of the users to the final product delivered; compounded by the diversity of desires held by the eventual users of project deliverables, and the lack of effective communication of requirements between users and developers and even among project team members has been reported as the root of many project failures (Li et al., 2011; Robertson and Robertson, 2006). Defining and managing traceability, the relationships between requirements, is another important component of managing requirements. Traceability is the ability to describe and follow the life of a requirement (both forward and backward) identifying a requirement and others to which it is related, and crucial for managing change and dependency (Brennan, 2009; Maciaszek, 2007). Brennan (2009) further states that traceability is a useful tool for performing impact analysis, which is performed to assess or evaluate the impact of changes.

Requirements management (RM) over the past decade has become an important focus in major product development industries such as: Software Engineering, Manufacturing and Aerospace. This has been recognized by Fernie, Green and Weller (2003) and Green et al. (2004) who both discuss that RM has a long history in the software development industry and is also used extensively within the Aerospace and Defence Sectors. Almefelt, Berglund and Nilsson (2006) conducted an empirical study of requirements management practice in the automotive industry with the aim to bring forward new experiences and knowledge. Sinha, Sengupta and Chandra (2006) studied and identified difficulties and challenges of managing requirements in a collaborative environment and proposed a tool to support software developments teams in collaborating on requirements management. Moser et al. (2011) conducted an empirical study on automated requirements categorization and conflict analysis with the aim of lowering the efforts associated with requirements management, in particular tracing requirements, conflicts and impact analysis amongst others. Previous research has considered the development of models that can facilitate the process. However, these are not specific to the construction industry. The client requirements processing model (CRPM) was developed to help in the definition of client requirements and the 
incorporation of the different perspectives represented by the client body, by systematic mapping or translation of the requirements from the business terminology ("voice of the client”) into design terms ("voice of the designer") to ensure requirements are presented in a solution-neutral format (Kamara, Anumba and Evbuomwan, 2002). CRPM has three stages. The last stage, translation of the requirements deals with transformation of clients requirements into design attributes. During all these stages, managing the elicited requirements is of great importance but it is apparent that the CRPM only feds into the design phase of a construction project but doesn't continue throughout the later phases of a project. Kiviniemi et al. (2004) and Kiviniemi (2005) working on requirements management presented a framework focusing on the requirements model and its interconnection to the architectural design model.

Recent research by Yu, Shen and Chan (2010) on requirements management in construction was driven to explore existing problems and potential solutions of managing Employers' Requirements in the project development process of construction projects under traditional procurement systems. Even though the paper provided valuable insight into the prevailing problems and potential solutions, it was focused on traditional procurement systems. Currently, with focus on integrated project delivery, there is the need to understand the complexities of requirements management and their effect on integrated projects, where teams and stakeholders are expected to collaborate and coordinate in an integrated approach of processes and systems to enhanced seamless exchange of requirements information, and how an integrated solution can be devised.

\subsubsection{Requirements Management - an Aspect of Construction Project Management}

Increasingly, client requirements management is perceived as a necessary project management activity for proper and disciplined management of the information regarding client needs and expectations of buildings from design, to production, operation and maintenance and, ultimately, disposal or decommissioning. Managing client requirements (including their communication) is not an easy task because of the large volume of information that comprises the requirements as well as inputs from the many different people involved in the process (Charoenngam, Coquinco and Hadikusumo, 2003). Managing requirements information is becoming more challenging and complex as a result of increasing needs and expectations of stakeholders. Rezgui, Zarli and Hopfe (2009) recognize that the construction industry is faced with the challenge of extremely demanding clients and users whose requirements of buildings vary considerably from one project to another. Information collected during briefing must be properly documented in order to enable effective communication among project team members (Pena and Parshall, 2001). This paper echoes that requirements information and their management are commonly dealt with and concentrated at the early phases of construction projects and become disjointed in 
subsequent phases. Once design begins and progresses, these requirements are left aside and the design is used to interpret client wishes. A similar observation is made by Kiviniemi et al. (2004), who state that building program documentation is the starting point of the design process but is usually left aside and all incremental changes are made based on the previous design solution. Kamara et al. (2002) also indicate that changes to requirements are recorded as corrections or additions to sketches and drawings as the main medium for representing the brief, and not on the original brief; making it complex to trace requirements to the original needs of the client. Ozkaya and Akin (2007) argue that rather than being considered as a front-end task or as an activity which is addressed marginally, requirements management has to be considered in correlation with form exploration, and as an inseparable part of design. Requirements are the source for design thus understanding, documenting and managing requirements effectively would facilitate not only proper design change management but any other requirements-related changes during a project life cycle. According to Hegazy, Zaneldin and Grierson (2001), it is complex to introduce design change and requires full understanding of the reasons (i.e., rationale) behind the original design, which helps in preventing any violation of the requirements of the original design. In order better to manage and utilize requirement changes all through a facility's lifecycle, it is necessary in the initial stage to adequately document and store the requirements information in a central repository.

The review highlighted key gaps and challenges. Firstly, managing client requirements information is still manual and paper-intensive. Secondly, there is no utilization of an integrated and centralized storage of client requirements information. This does not facilitate collaborative access to the most current version of requirements by the various stakeholders. It does not also enhance integrated project delivery. Thirdly, requirements change constantly during the life of a facility, however, change management models and systems identified did not specifically focused on client requirements information management. The systems did not also take a lifecycle information-centric approach. Fourthly, limitations were highlighted regarding the management of changes which include manual checking of dependencies, lack of updating the originally sets of requirements after changes are authorized and notifications not widely communicated. This necessitated for adequate management efforts to control and coordinate the change management process. Traceability of requirements is crucial in facilitating impact analysis which can be enabled by dependency links. Consequently, this paper argues that an adequately developed and maintained requirements information management system, supported by a standardized and established process for the projects, will support the efforts of lifecycle requirements management in order to contribute to successful construction projects. 
AK Jallow , P Demian , AN Baldwin , C Anumba , (2014) "An empirical study of the complexity of requirements management in construction projects", Engineering, Construction and Architectural Management, 21( )5, 505 - 531

\section{Research Methodology}

The research reported in this paper was designed to achieve a better understanding of managing client requirements information over the lifecycle of constructed facilities by identifying the critical factors of good management of client requirements which contribute to successful projects (i.e., projects that meet budget, cost and quality as specified in the client requirements). A review of different research paradigms, methodologies, strategies, and data collection methods was conducted and the most appropriate were selected for the research. Various considerations played an important role in this decision, amongst which was the research problem (Creswell, 2009). However, methodological decisions were also dictated by certain practical circumstances such as availability of data; access to the social set-up to be studied (i.e. construction projects) to conduct case studies; and the availability and willingness of participants to participate. Another important consideration was the purpose of the study which was a combination of exploratory, descriptive and explanatory in order to be able to understand the method of requirements management and to define an innovative and better approach.

Qualitative methodology and interpretative paradigm of inquiry were adopted because of the nature of the research which requires the study of interaction between people within a construction environment (social set-up) in order to understand how they execute client requirements information management. This family of research methods involves using research strategies such as case study, grounded theory and/or ethnography; employs data collection methods such as interviews, observations, questionnaires amongst others to conduct findings which can be expressed in words (Robson, 2002; Gray, 2009). According to Gray (2009), interpretive studies is used to explore peoples' experience and their views or perspectives of these experiences; and is characteristically inductive in nature and often associated with qualitative approaches to the collection and analysis of data.

Because of the importance of depth over breadth in this research, a case study method was chosen as the primary research strategy of inquiry. A case study entails the detailed and intensive analysis of a single case or multiple cases where a case is interpreted very widely to include the study of an individual person, a group, a setting or an organization (Robson, 2002; Bryman, 2008; Gibson and Brown, 2009). As a result, a case study of a leading international global built asset and engineering consultancy organization, which specializes in project management amongst other things, was conducted over a two year period. The organization helps clients make the most from their investment and expenditure in built assets, which includes managing the client requirements of building projects. The selection of the case was based on the purpose of the research, the data collection methods, available time to conduct the research, resources and accessibility to the cases' environment. This case study was chosen based on the following criteria: (i) 
access to public institution projects; (ii) project management organization having either good or poor client requirements management; (iii) managing projects with different contractors; (iv) organization with history of successful project implementation. Consequently, the research was designed to focus on this case organization, which project-managed three different projects during the period. However, the aim was to follow the engineering organization to learn and understand an industrial approach to managing client requirements to help identify the issues which contribute to the complexity. The research followed the organization in all three of the projects they were managing at the time. All the projects (Project A, B and C) were public institution buildings.

The case study was principally conducted using semi-participant observations which were supplemented with other methods such as interviews and document analysis. The main factor for selecting the case study approach was to enable an in-depth examination and analysis of the process of managing client requirements as applied in the context of construction projects. Qualitative data collection methods (interviews, observations and collection of documents) have been used for the data collection for this research. During this period, project meetings, periodic progress meetings and design team meetings were convened to discuss the progress of the project. These were attended by the clients (or their representatives), contractors, architectural designers, structural engineers, external project consultants and other stakeholders. Observations were made during a two year period whilst the projects were under development (i.e., from 2008 to 2011), including the development of the proposed framework. Audio recordings of the proceedings were taken as well as the many hand written field notes.

Interviews with selected individuals were held. In total fourteen separate individual interviews were conducted: six client project managers; two construction managers; two project managers from the external consulting company; two architects and two facilities managers. Six of the interviews (conducted with four project managers and two construction managers) were pre-planned semi-structured interviews with the help of a questionnaire to guide the interview. These lasted not more than an hour. The remaining eight interviews were conducted as a follow-up to the observations and were randomly carried out depending on emergent issues observed during the meetings. All interviews were audio recorded and transcribed which resulted in large amount of qualitative data to facilitate the analysis. Documents relevant to requirements information were also collected and examined. Table 1 shows the various types of documents collected and analyzed. It details the actual documents (not templates) with the information contained in those documents and the significance of their collection and analysis with respect to requirements management. 
Thematic analysis was used to analyze the data collected (Swenden, 2006; Boyatzis, 1998). It is regarded as one of the most common approaches to qualitative data analysis which often attracts a coding approach (Bryman, 2008). Coding involves the breaking down of data into separate pieces and regards the creation of categories and classification of data by grouping them together in a sort that can enable them to be regarded as the same (Charmaz, 2006). Themes are more or the less the same as codes and the process involves constructing themes and subthemes which are often generated after thorough reading of the transcription and field notes that make up the data (Gray, 2009; Bryman, 2008).

Table 1: The different types of documents collected and analyzed

\begin{tabular}{|c|c|c|}
\hline $\begin{array}{l}\text { Types of } \\
\text { documents }\end{array}$ & $\begin{array}{l}\text { Information captured } \\
\text { and examined }\end{array}$ & Significance \\
\hline Brief & $\begin{array}{l}\text { - The different } \\
\text { requirement attributes } \\
\text { - Rationale and priorities } \\
\text { of requirements } \\
\text { - Relationships between } \\
\text { requirements }\end{array}$ & $\begin{array}{l}\text { It was relevant to understand the different } \\
\text { attributes used and why. It is also important to } \\
\text { understand rationales of requirements which } \\
\text { will help determine why they were generated } \\
\text { and their priority in terms of implementation. } \\
\text { Relationships between requirements will also } \\
\text { help understand the link, dependency between } \\
\text { requirements for traceability purposes. }\end{array}$ \\
\hline Minutes & $\begin{array}{l}\text { - Attendees } \\
\text { - Distribution } \\
\text { - Requirements changes } \\
\text { requested }\end{array}$ & $\begin{array}{l}\text { It was important to review minutes as they } \\
\text { serve as reference materials on decisions made } \\
\text { on changes during meetings. They also show } \\
\text { the people who attended which is helpful to } \\
\text { determine the different stakeholders who were } \\
\text { involved in the process. }\end{array}$ \\
\hline $\begin{array}{l}\text { Change Order } \\
\text { Forms }\end{array}$ & $\begin{array}{l}\text { - Originator } \\
\text { - Change proposal } \\
\text { - (reason for change) } \\
\text { Rationale } \\
\text { - Effect on cost and time } \\
\text { (impact) }\end{array}$ & $\begin{array}{l}\text { These forms are the primary carrier of change } \\
\text { information. Thus it was crucial that they were } \\
\text { examined and analyzed thoroughly. }\end{array}$ \\
\hline Emails & $\begin{array}{l}\text { - Originator } \\
\text { - Distribution (cc) } \\
\text { - Requirements changes } \\
\text { requested }\end{array}$ & $\begin{array}{l}\text { Emails served as a valuable and desirable } \\
\text { communication tool in all the projects managed } \\
\text { by the case study organization. The study of } \\
\text { emails was necessary to understand how } \\
\text { exactly they were utilized and the content they } \\
\text { carry. }\end{array}$ \\
\hline $\begin{array}{l}\text { Progress } \\
\text { Reports }\end{array}$ & $\begin{array}{l}\text { - Project status (in terms } \\
\text { of requirements } \\
\text { implemented and those } \\
\text { out-standing) }\end{array}$ & $\begin{array}{l}\text { These reports show the different stages a } \\
\text { project was and describes the various level of } \\
\text { completion. They were important to study to } \\
\text { reveal how client requirements were } \\
\text { implemented. }\end{array}$ \\
\hline $\begin{array}{l}\text { Project } \\
\text { Manager }\end{array}$ & - Description of & $\begin{array}{l}\text { These instructions govern what work to be } \\
\text { implemented following a change request. Thus }\end{array}$ \\
\hline
\end{tabular}


AK Jallow , P Demian , AN Baldwin , C Anumba , (2014) "An empirical study of the complexity of requirements management in construction projects", Engineering, Construction and Architectural Management, 21( )5, 505 - 531

Instructions instructions it was necessary to study and determine their

(PMI) - Cost and time effect content in relation to the corresponding information on the change request forms.

The data collected were thoroughly examined and categories established. Similarities in the data were identified which resulted in the grouping of similar data under different categories. These categories were further classified, coded and sub-divided into different key themes relevant to providing answers to the investigation. These themes shown on Table 2 formed the basis of the analysis upon which the emerging theory was based.

Table 2: Data analysis themes

Theme Rationale

Documentation and Storage (requirements information)

Access and Distribution (requirements information)

Requirements Change Process

Communication and Distribution (change information)

Dependency Checking and Impact Analysis

Traceability and auditability
To understand the mechanisms for requirements capture and storage.

To understand how different stakeholders access, use and disseminate the requirements information to each other

To understand the change process, identify the different tools or techniques used for requesting requirement changes, and to find out if errors occur during the change process and to identify the sources of such errors.

To identify the different mechanism/channels of communicating changes.

To understand how dependencies between requirements are traced and managed, and how impact was analyzed.

To find out the mechanisms for tracking individual requirements and tracking them to their original and later phases (i.e., both backward and forward traceability), and how the process is audited in case of changes.

Following the development of the proposed framework, its evaluation was carried out within a six months period in 2010/2011. During the evaluation, the framework was presented and all components described in detail. Discussion was also carried out on how the components solve the defined problems in an integrated manner, and the participants were able to use it with test data. The evaluation results were captured using a questionnaire distributed and completed by the participants. 
AK Jallow , P Demian , AN Baldwin , C Anumba , (2014) "An empirical study of the complexity of requirements management in construction projects", Engineering, Construction and Architectural Management, 21( )5, 505 - 531

\section{Presentation and Discussion of the Findings}

Key themes were identified from the case study to form the basis of the presentation and discussion of the data, as shown in Table 2. Critical analysis was made of the case in various areas of requirements information management according to the themes as applied in the project management process. Although the requirements managements problems/difficulties/complexities found in the case are specific to the projects that were project-managed by the case study organization, this paper recognizes that the complexities stem from the inherent difficulties of general requirements management in the construction industry.

\subsection{Requirements Documentation, Storage and Distribution}

The key focus of these areas was to find out: (i) the documentation and storage mechanism of requirements information; (ii) if requirements were accessible to all parties; (iii) the access mechanism; (iv) how requirements were communicated/distributed.

Both literature and the case study showed that in the construction industry client requirements management is currently manual and paper intensive. Client requirements were elicited as a brief and documented in a text document using a word processor with no central storage and accessibility to all team members. This document was distributed to various parties (the Project Management Board, Consultant Project Manager, Internal Project Manager, and the Architect) in different formats and media (e.g., hard copy, digital documents, etc.). A large amount of the information (more than 90\%) produced after the production of the brief was generated during meetings. This information was documented as minutes in text documents and disseminated in paper-based form to the relevant stakeholders. The architectural designer used this information along with the original brief to produce sketches and drawings. Once the initial design was developed in the early stages (RIBA Stage C), requirements documentation was not usually updated on the brief document in later phases and new and emerging requirements were not communicated to all other stakeholders at the right time. This created an atmosphere where different teams (e.g., the designer and M\&E team) worked with different versions of requirements. A major factor of the complexity relating to documentation, in particular the use of paperbased approach is the lack of a central storage mechanism to facilitate access to a single and up-to-date source of the requirements. Communicating and distributing requirements is challenging and complex in an integrated construction project environment. However, it contributes to the effective management of the requirements and critical to the success of projects. Drawings were then distributed to the relevant stakeholders again in paper-base. Because drawings were most often 'hard copies', they were scanned before eventually being sent to a recipient. One of the primary mechanisms for communicating and 
distributing client requirements was through the use of e-mail with attached documents (e.g. the brief, minutes and drawings).

On very few occasions, for example in one of the projects, drawings were uploaded to a project extranet for access by all stakeholders. However, even though this project extranet existed, it was not commonly used for accessing and distributing client requirement documents. Instead, the client, design and construction teams relied heavily on hard copies and e-mail messages with attachments for sending and receiving such documentation. Teams were aware of security issues associated with sending documents as attachments and wanted to ensure that the information provided was not changed on receipt. Accordingly, word processed documents were frequently converted to Portable Document Format (PDF) before being sent to prevent distortion or change to the information. CDs, DVDs and other electronic storage devices were used to store requirement documents and distribute to relevant stakeholders. It is complex to use hardcopies to communicate requirements and their related information, which was observed to have a negative impact on the efficiency and progress of the projects and their management. The observations revealed how sometimes the change control forms detailing requested changes would not be in hand during project meetings for discussion and approval. This affected any other decisions that had to be made in relation to those changes under review.

The observations also highlighted the use of the telephone as a communication mechanism whereby amendments to requirements and sometimes queries were verbally communicated becoming very complex to manage. This was seen as an easy way of communicating requirements but undoubtedly is very ineffective in ensuring auditability, traceability and visibility of requirements. Different teams and stakeholders have an interest in specific requirements at different phases thus requiring information to be documented in a manner that is comprehensible to all concerned. In order for requirements communication to be successful and to avoid information overload, the right sets of requirements relevant to the individual project team should be put together and packaged in the appropriate structure.

The findings lead to the view that a database management system could and should be used as a central repository to manage the requirements. This would enable an information-centric orientation (i.e., managing the content of documents) instead of the conventional document-centric orientation to the management of requirements information. Variable stores of data with individual stakeholder's requirements together with their parameters could be stored to enhance traceability and version control. This would be much easier than a document based, and requirements management systems within construction firms should be able to provide collaborative working not only a standalone application 
system. Such systems would need to be Web-based to facilitate collaboration within geographically dispersed teams involved in the construction projects.

\subsection{Requirements Traceability, Dependency Checking and Impact Analysis}

No recognizable system was observed to have been used for traceability, which is relevant to provide dependency checking for impact analysis. Current document-centric requirements management (i.e., managing the documents/files holding the requirements as a whole instead of the content) within construction makes it very complex to manage traceability. This was further manifested by the questionnaire respondents used to understand the change management process. In one of the questions, respondents were asked the following question:

Question: "How do you assess impact of the changes in relation to other requirements?" Two of the respondents stated:

Respondent 1: "This is discussed at the Site and Design meetings prior to the preparation of the necessary paperwork, should it be agreed that it is a necessary change. Changes impacting on costs and programme are designed out so as not to, thus ensuring any sign off is a formality and does not delay the process."

Respondent 2: "Request for changes are considered in terms of the cost, programme and brief impact. Furthermore key parties including the client are consulted with regard to the impact of the change on the brief and the impact on other requirements."

Clearly, these responses do not indicate how impact on cost and time is assessed nor do they illustrate a dedicated tool for that purpose. In fact entirely, the documentation and storage mechanisms used did not in any way support traceability between requirements thus dependency checking was manually conducted. Impact analysis was done based on expert judgment by utilizing individual expertise and experience of past projects to determine dependencies and traceability between requirements; and often discussed during design meetings.

During one of the project meetings, extra toilets were added to the design as a result of the maximum occupancy figure of the building which was not known to the meeting beforehand. Consequently, this addition impacted on the original building services requirements. However, this impact could not be analyzed during the meeting as the $M \& E$ requested time to look into it. Analysis of the type of requirements information required at each project phase highlighted how the nature of the information varies from phase-to-phase. A key issue of the complexity of managing the requirements identified is that there is no mapping of requirements information between the phases. This makes it extremely difficult to 
manage dependencies and traceability between them. Dependency checking for impact analysis was adhoc, and carried out by manually. This manual process was not only tedious and laborious but time consuming and error prone, and this increases the complexity. With all pre-contract change orders, the consultant project manager and his/her cost consultant/quantity surveyor will review and provide time and cost implications. However, they would require information from the design team about the impact the change will have on the design. As a result, both the design team and consultant project manager manually checked for dependency of the changing requirement from different sources for possible impact. This process as stated earlier was inefficient. Getting access to all the relevant information necessary for the dependency checking could be impossible. Another major complex issue was that the change order form did not make provision for the capture of the particular requirement that was changing. The 'change proposal' field on the form (a description of the proposed change) is not enough for adequate dependency checking; and tracking either 'forward' or 'backward' traceability of the change. From the research, it is clear that sufficient information that would pinpoint the exact requirement changing as a result of the proposed change will be ideal to trace all other requirements and components that have dependency with it. Such information could be the changing requirement which can be identified by a unique identifier of the requirement. This information is not currently included on the change order forms used to request changes as observed. As the initial client requirements are documented in the brief, the information needs to be stored in a purpose built repository which facilitates shared and distributed access. Consequently, all subsequent types of requirements and project information should be mapped to their origins within the program/brief document. This will facilitate the traceability of dependencies between requirements at all phases through the project lifecycle.

\subsection{Requirements Change Process Management}

As observed, the client requirements were not static; they changed several times during design and construction. Periodically, design meetings were held to review progress and check that the drawings fulfill the client requirements. During that process, suggestions were made by the Architect which resulted in additions of new requirements or amendments to existing ones. Those became changes to the requirements which then went through a request for change process. Observations reveal that changes to client requirements were initiated by different parties and the channels indicated in Table 3 were identified to be used.

Table 3: Channels used for requirements change request 


\begin{tabular}{ll}
\hline Telephone & $\begin{array}{l}\text { Requesting a change by calling and discussing the } \\
\text { change but a formal change request accompanied with a } \\
\text { change control form will have to be raised }\end{array}$ \\
\hline Online Forms (eForms) & $\begin{array}{l}\text { Using an internet based form to request a change (not } \\
\text { used extensively in the case) }\end{array}$ \\
\hline Email & $\begin{array}{l}\text { Sending an Email with all change details and necessary } \\
\text { supporting documents as attachments }\end{array}$ \\
Meetings & $\begin{array}{l}\text { Requesting a change during design and or project } \\
\text { progress meetings }\end{array}$ \\
\cline { 2 - 2 } Face-to-face(individually) & $\begin{array}{l}\text { Meeting with an individual and verbally requesting a } \\
\text { change but a formal change request accompanied with a } \\
\text { change control form will have to be raised }\end{array}$ \\
\hline Paper-based (hardcopy) & $\begin{array}{l}\text { Using hardcopies of change order forms and sending } \\
\text { them through the post }\end{array}$ \\
\hline
\end{tabular}

This was also confirmed in the interviews as shown in responses to a question in which respondents were asked the questions below:

Question: Requirements are constantly open to change throughout the lifecycle of a project. Different stakeholders may initiate a change through different channels such as meetings.

a. How are changes initiated and what medium of representation is used for this?

b. When changes are implemented, how is the information reflected to the initial requirements?

c. How are the changes communicated to all stakeholders?

\section{Two respondents stated:}

Respondent A: "A client can initiate a change by sending a request for change by an e-mail to myself (Project Manager) asking for a quotation as a result of the change. We respond by telling the client whether we can implement the change or not and we provide a quote for it. The External Project managers will then be informed who will issue instructions to us on behalf of the client.

We, as the contractor, can also request a change by going directly to the client and 'PM' detailing the change. The design team is copied the correspondence of the change requests and that will result in a drawing being revised by the Architect or Structural Engineer. That revised change drawing will then be sent for approval by the client and to all stakeholders." 
Respondent B: "Both client and contractor can request for a change to the initial requirements and as said before, this should go through the normal changes process using hardcopy. We sign hardcopies and convert them to PDF files and send to other parties.

Yes, let's say if the color of the chairs change, then the Architect will re-issue a drawing which will indicate that the colors have changed. They wouldn't necessarily go and change the specification. In a more complicated project such as T5 (Heathrow Airport), the change request would be more complicated and may request a lot of signatories. That would be a good place to find out.”

This manifested the various stakeholders can request a change which according to the second interview respondents goes through a change process. For example, in one of the projects, the client initiated changes in building space requirements, fittings, and electrical materials. Likewise, the contractor initiated changes to some materials due to market availability which all went through the normal change process. Whoever initiated a change, a change request form was filled and the approval process followed.

\subsubsection{Change Request and Control Process}

The client, contractor or any member of the project team could request a change by raising a 'request for change' (RFC) form otherwise captioned and referred to as 'change order' or 'change control' by completing sections 1 and 2. The form is made up of different sections (as shown on Table 4) which need to be completed by different parties depending on their roles.

Table 4: Different sections and parts of the RFC form

\section{Section Information captured/detailed}

Section 1

Project details including: project name, Sponsor, project manager, originator of request, job no., change request no.; charge code and date of request.

Section 2, Part 1 Change proposal describing the changes, supporting documents and reason for the change.

Section 2, Part 2 Effect on cost

Section 2, Part $3 \quad$ Effect on delivery timescale

Section 2, Part $4 \quad$ Consequences of rejecting change request 
AK Jallow , P Demian , AN Baldwin , C Anumba , (2014) "An empirical study of the complexity of requirements management in construction projects", Engineering, Construction and Architectural Management, 21( )5, 505 - 531

Section 3 Change approval from those who may be affected by the change. Note: request will still need final approval.

Section $4 \quad$ Final change request approval/rejection detailing name of authority, signature and date.

If the request is made during the construction phase, the Contractor completes sections 1 and 2 . The form is then sent to the consulting firm managing the project on behalf of the Client with all other supporting documents. The 'Quantity Surveyor' (otherwise referred to as the 'Cost Consultant') and the 'Consultant Project Manager' check the information for cost and time implication. If they consent to the information, the form is routed to the stakeholder(s) to whom the RFC is relevant. When the consulting firm receives approval from the stakeholder(s), 'Section 3' would be completed by their representative. When this is done, the RFC is then issued to the 'Client Project Manager' for final authorization. The 'Project Management Board' is responsible for this final authorization by approving or rejecting the RFC. This will be confirmed by the 'Client Project Manager' to the consulting firm by completing 'Section 4'. The 'Consultant Project Manager’ will then issue a 'Project Manager Instruction’ (PMI) to the 'Contractor' for implementation. Otherwise if the RFC is a pre-contract (before contractor is appointed) request, the process remains the same except that the RFC can either be raised by the 'Designer' or the 'Client' who will complete 'Section 1' and 'Section 2-Part 1'. The 'Consulting firm' will then complete 'Section 2Parts 2, 3 and 4' and the process proceeds as described above.

No matter what the implications (negative or positive impact) are, the change request would then proceed to the client for approval and the change initiator is informed of the decision. It must be made clear that during an interview with some of the case study team members, it was clearly pointed out that the RFC process described and used were specific to the particular projects studied. They further highlighted that this process is more complicated than some of the other change process systems and processes used in other projects they had been involved in. It is also worth noting that this process is not necessarily representative of the whole construction industry. It is presented and used for analysis and demonstration purposes as the de-facto process used in the case study organization. However, the findings indicate 
relevant issues in managing client requirements and their changes, which are indeed general to the construction industry no matter the type of project and project management method employed. A total of 260 change orders were processed by the case study organization during the period. This is a significant number and these change orders carried a vast amount of requirements information including the description of the changes and their rationale which is needed in the later phases of a building especially at operations. Thus, this contributes to the complexity of managing requirements and indicates the importance of managing change orders of which processing could prove to be a challenge. Figure 1 shows the number of change orders recorded during the period of the case study according to the projects managed by the case study organization.

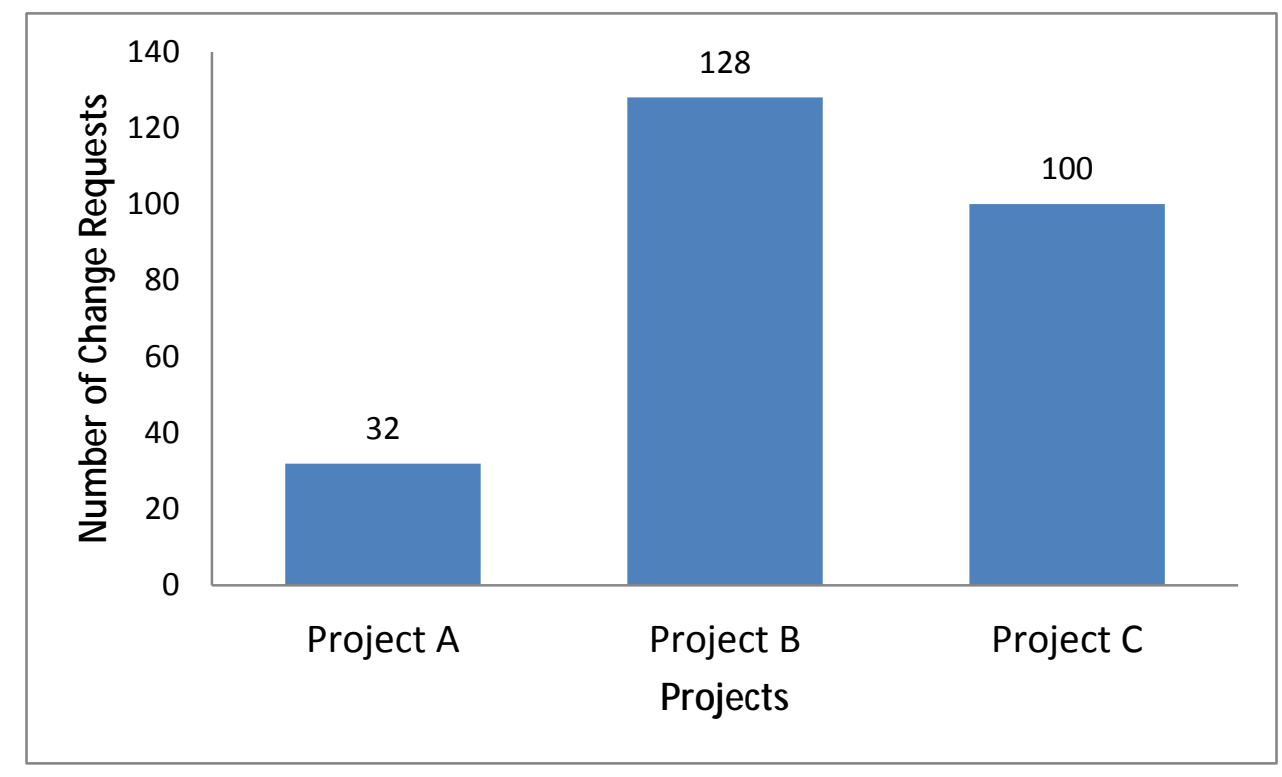

Figure 1: Number of change orders during the observations

It was observed that different stakeholders attended different project meetings during which decisions were made on changes to client requirements. Paper-based forms of approval were frequently ineffective. Vast amounts of information on such decisions were kept in personal memories during the meetings and eventually lost over time. This created complexity to revisit rationale of change decisions and challenge of auditability of the process. 
AK Jallow , P Demian , AN Baldwin , C Anumba , (2014) "An empirical study of the complexity of requirements management in construction projects", Engineering, Construction and Architectural Management, 21( )5, 505 - 531

\subsection{Communication and Distribution of Requirements Change Information}

When requirements changes are requested and approved, the information including up-to-date client requirements should be communicated as wide as possible to ensure teams do not work with outdated sets of requirements. Email, often with PDF attachments, and distribution of hardcopies was the main media used to communicate requirements change orders, and was preferred by the respondents of the interviews as shown in Table 5. Often, text documents are converted to PDF files before they are sent as Email attachments. Project teams, for example, the design team upon receipt of the change notification and approval, effects the change on the design by revising the appropriate drawings. These drawings are then distributed again as described earlier by Email or hardcopies. However, despite Email being the favorite choice and used hugely, there were inefficiencies and ineptitudes associated with its use, which compounded the complexity of managing the requirements. It was observed that visibility and auditability of the change process, which is catalyst in any change management, is virtually impossible to achieve with the use of Email applications as they were not designed for task management.

The ineffectiveness of Email as a change communication tool also relates to access to the information when required. A scenario was observed when change request forms were sent for approval. The forms were printed and approval granted, however they were left back and not brought to the meeting for discussion. There were times when Emails with attachments are sent but some team members claimed not to have received them. Similarly, some claimed not to have received or not able to access the attachment. Requirements management requires task process management, traceability, visibility and an audit trail of requirements changes and their impacts. Email does not provide such functionality. Nonetheless, whichever tool is used, the process should be well documented and information traceable for visibility and audit purposes. Improving the requirements change management process, procedures and activities remains a critical success factor for construction organizations for improved delivery of facilities. The significance of a structured methodology for managing the change request process cannot be 
overemphasized. For that reason, establishing a robust change management mechanism supported by reliable and dynamic technology could be a catalyst to good requirements change management.

There were other technical issues relating to the use of Email that made it difficult to communicate and distribute changes effectively between stakeholders. For example, it was discovered that the client organization's IT policy limits the size of Email attachments. As a result, there were some changes that needed drawings to be attached to support and also show the rationale of the changes to the client. However, because of that limitation the Email was not the best tool to use in that particular incident and the project reverted to using hardcopies for that purpose.

Table 5: Main and preferred channels to communicate change orders

\begin{tabular}{ll}
\hline Respondent & Medium used to communicate changes \\
\hline Respondent A & Email \\
& Hardcopy \\
Respondent B & Email \\
& Hardcopy \\
Respondent C & Email \\
& Digital document (PDF) \\
Respondent D & Email \\
& Hardcopy \\
Respondent F & Digital document (PDF) \\
& Email \\
Respondent G & Email \\
& Digital document (PDF) and Hardcopy \\
\hline
\end{tabular}

Two different requests for change processes were observed, which were paper-based and the approval process often took a long time before final decision was made. There was the (i) pre and (ii) post contract award request for change processes. Both were studied thoroughly during the case study period. They both followed the same routine but their main difference is that a contractor is not involved in the precontract request for change. Most of the requests for changes were pre-contract change requests. This was because most changes relating to client requirements were generated and dealt with at the earlier phases (preparation, design and preconstruction). This does not mean that client requirements did not change 
over the later phases. The research focused mainly on changes requested during the design and construction phases. Understanding the general change process used no matter at which phase was sufficient enough for this research.

\section{Summary and Implications for a Framework}

Client requirements are the basis for design and construction and all other project management activities. However, this paper recognizes that requirements management is often an underutilized project management activity in construction industry. The research reported in this paper recognizes that developing an effective client requirements management process is a challenging task because it requires an integrated approach. This requires consideration of coordinating everything involved for the purpose of managing requirements efficiently and effectively. From the studies carried out, the following points summarize the findings and complexities associated with client requirements management.

- First, client requirements were not managed all through-life of buildings (i.e., the requirements were not managed at each phase of construction projects across the lifecycle). Instead, only applied during the early phases (preparation and design) and then the design is used subsequently to translate client requirements.

- Second, it was identified that client requirements were not centrally documented and stored. As a result, various sets of requirements were held in different locations by different people. Most of those requirements were outdated as updating all the copies with everybody in the project development team was virtually impossible.

- Third, access to the requirements by all project stakeholders for their use in the construction process was difficult because of lack of an integrated and centralized repository.

- Fourth, the dynamic nature of client requirements meant that they evolved as projects progress and their management was a routine and iterative process involving a number of people (who are based in different geographical locations), processes and systems. However, this process was manual and involved numerous paperwork which lacks efficiency and effectiveness. Sometimes 
delays were caused during this process which occasionally affected progress of projects. The change process would also require checking for dependencies between requirements in order to ascertain impact of changes. The paper observes that whilst requests for changes have been carried out in projects, for it to be efficient and effective, the process must be adequately streamlined for a more robust coordination and control between people, and the systems used for information processing such as workflows.

- Fifth, dependency checking and assessment of impact was manual and involves physically checking for all paper work and in systems that hold requirements. This is time consuming, laborious, and ineffective as sometimes it is impossible to trace all dependent requirements. The process is also cumbersome because of the many people involved and this makes the coordination and control very difficult. Often, there is no visibility to the process and auditability is very rare as history of the information is not accurately captured and stored. However, some advances have been made to document and store change requirements in databases but there is a lack of coordination between the formal change process and dependency checking thus lacking efficiency. The paper therefore argues the functionality of dependency checking should be integrated within the change management process.

- Sixth, where information systems were used to document, store and manage the requirements information, another major complexity that was also identified was the lack of integration and interoperability between those systems. Requirements information cannot be seamlessly shared and exchanged between the systems.

Finally, the paper suggests that the construction industry should:

- Consider requirements information management as a lifecycle process and not to be focused in the early phases only. This will make sure the needs and wishes of the client are adequately carried forward in all phases and effectively managed. This will be useful in reducing 
AK Jallow , P Demian , AN Baldwin , C Anumba , (2014) "An empirical study of the complexity of requirements management in construction projects", Engineering, Construction and Architectural Management, 21( )5, 505 - 531

assumptions, claims and disputes as the likelihood of producing quality facilities that will meet the needs of client and users will be very high.

Make a paradigm shift to documenting and storing requirements information in a manner that will facilitate its effective management. This should focus on moving from the traditional paper based documentation to using dedicated information management solution encapsulated as a component in a Building Information Model (BIM). This is relevant because very few studies have addressed the integration of requirements management functionality with BIM models.

- Such a system should support collaborative access to the requirements and their updating. The system should also be interoperable to enable information exchange various systems; sharing and communicating requirements information between all stakeholders. This is crucial because current systems used in the construction industry are heterogeneous and mostly not interoperable, making it difficult to exchange and share construction information such as requirements. This will provide an approach to better management of the whole lifecycle client requirements information in a manner that can integrate people, processes and systems.

- The industry should consider the viability of implementing requirements information management systems, which will be interoperable to enable sharing and communicating requirements information between all stakeholders. This is crucial because current systems used in the construction industry are mostly not interoperable making it difficult to share construction information such as requirements between heterogeneous systems.

- The industry must regard requirements information management as a lifecycle process and not to be focused in the early phases only. This will ensure the needs and wishes of the client are adequately carried forward in all phases and effectively managed. This will be useful in reducing assumptions, claims and disputes as the likelihood of producing quality facilities that will meet the needs of client and users will be very high. 
AK Jallow , P Demian , AN Baldwin , C Anumba , (2014) "An empirical study of the complexity of requirements management in construction projects", Engineering, Construction and Architectural Management, 21( )5, 505 - 531

- Within the construction industry, there is currently no standard role responsible for specifically managing client requirements. Given the difficulty of managing client requirements, it is recommended that introduction of 'Requirements Manager' role be incorporated within the project team which is important in contributing towards successful projects. This role could shift between individuals as the lifecycle progresses from one phase-to-another. However, this may depend on several factors such as client preferences and project procurement type amongst others.

The paper recommends that effective management of client requirements requires a better approach to manage the complexities. The approach should (i) define a structured approach to a web based centralized repository that can facilitate collaborative and distributed access to the client requirements; (ii) specify a mechanism for managing the traceability relationships between requirements at all phases of a facility, which can facilitate dependency checking between requirements; crucial for impact analysis, and cost and time assessment; (iii) facilitate integration and interoperability for requirements information flow and exchange between all stakeholders and applications use for requirements management across the whole lifecycle of a building; (iv) enhance the requirements change management process through efficient and effective coordination of the people, information and systems; (v) improve the current manual mechanism of dependency checking in order to facilitate impact analysis of changes to the requirements. In order to do that, the paper proposes an integrated framework as shown in Figure 2 (i.e., the Electronic Requirements Information Management (eRIM) framework), to facilitate the process. 


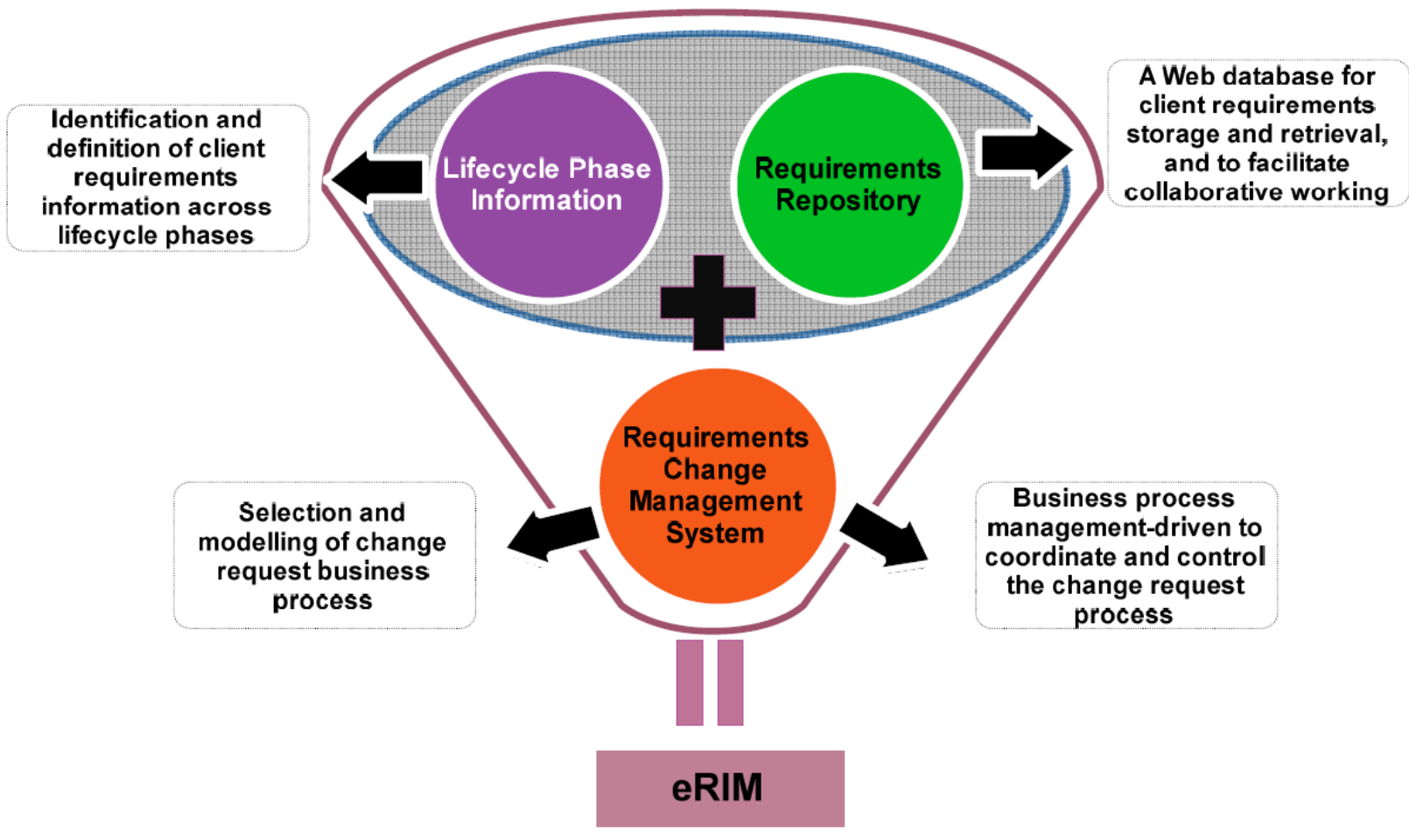

Figure 2: High-level view of the main components of eRIM Framework

eRIM can provide a defined and controlled requirements management process that registers client requirements from program document stage, through design and construction and all through the life of the facility. It can ensure that details of client requirements are available at all times; provide a history of previous changes to requirements and enables the project manager to manage changes effectively through a defined and controlled change management process. The framework comprises two main components, considering the key elements (i.e., storage, access and retrieval; communication and distribution; change and dependency management and traceability, visibility and auditability) to effective client requirements management. It is also aligned to current efforts on integration and interoperability between applications in the construction industry. The basic components are: (i) a requirements repository, and (ii) a change management process and system to manage the requirements change requests and approval process. It has a supporting scheme which defines requirements information to be identified for each of the project/facility lifecycle phases. It specifies stakeholders involved in the requirements management 
process and identifies communication channels for requirements and associated changes. Because of the challenges of integrating different construction information management systems, the framework also defines an integration procedure based on existing technologies. Four key principles of organizational management feature in the framework. These are: information management, collaborative work, process management and change management. The full details of the framework including its evaluation are beyond the scope of this paper. However, a critical aspect of this research was the mechanism to test and evaluate the proposed framework, which included industrial input and assessment. Since the framework was aimed at improving the requirements management process, it was considered fitting to provide an evaluation in order to determine how it can affect the current mechanism of requirements information management. It was relevant and also appropriate to involve industry experts and practitioners to interact with the framework in order to determine its relevancy to industry. Results from the evaluation indicated huge potential benefits of the framework, and implementing a system based on it. The results also indicated overwhelming interest from the participants to consider possibility of implementing the change management system component of the framework as a drive to automate the approval process of change requests. According to the evidence, it is anticipated that when fully implemented, the significant benefit which the framework and associated system can deliver is efficiency and effectiveness and improvement of the quality of the requirements management process.

\section{Conclusions}

Client requirements information management in construction projects is still largely manual and paperintensive and this does not prove to be efficient and effective. There is no utilization of an integrated and centralized storage of client requirements information. This does not facilitate collaborative access to the most current version of requirements by the various stakeholders. It does not also enhance integrated project delivery. Managing the requirements documents is not applied across the entire lifecycle phases. Once the initial design is developed, the brief/program is put aside and is not carried forward into other phases of the construction project. Emergent and changing requirements are incorporated within the 
AK Jallow , P Demian , AN Baldwin , C Anumba , (2014) "An empirical study of the complexity of requirements management in construction projects", Engineering, Construction and Architectural Management, 21( )5, 505 - 531

design and are rarely updated in the original brief. The change management process including dependency and impact analysis is ineffective. These issues cause challenges caused by several complexities. This paper reported on the complexities and proposed an integrated framework (eRIM), which defines a holistic approach to lifecycle client requirements information management.

The main limitation of the research is the use of a single organization, which applied the same project management method across all the projects they managed. It is thought that the approach and mechanism of managing client requirements could be different from project to project and from client to client. It would have been useful to explore other project management approaches to managing client requirements which could potentially draw out a different perspective. The research was also conducted within public institutional building projects only, which can limit the generalization of the results. However, despite these limitations, the relevant issues in managing client requirements are indeed general no matter the project management method or the type of building project, and those have not been compromised in this research. Further work is planned to develop the proposed framework fully, evaluate its industrial applicability with construction projects, and develop a software platform to operationalize it.

\section{References}

Almefelt, L., Berglund, F., Nilsson, P. and Malmqvist, J. (2006), "Requirements management in practice: findings from an empirical study in the automotive industry", Research in Engineering Design, Vol. 17 No. 3, pp. 113-134.

Anumba, C.J., Ugwu, O.O., Newnham, L. and Thorpe, A. (2002), “Collaborative design of structures using intelligent agents”, Automation in Construction, Vol. 11 No. 1, pp. 89-103.

Aouad, G. and Arayici, Y. (2010), Requirements Engineering for Computer Integrated Environments in Construction, Wiley-Blackwell, Oxford.

Austin, S., Baldwin, A.N. and Steele, J.L. (2002), "Improving building design through integrated planning and control”, Engineering, Construction and Architectural Management, Vol. 9 No. 3, pp. 249-258.

Bouchlaghem, N.M., Kimmance, A.G. and Anumba, C.J. (2004), "Integrating product and process information in the construction sector”, Industrial Management and Data Systems, Vol. 104 No. 3, pp. 218-233.

Boyatzis, R.E. (1998), Transforming Qualitative Information: Thematic Analysis and Code Development, Sage, Thousand Oaks, CA and London. 
AK Jallow , P Demian , AN Baldwin , C Anumba , (2014) "An empirical study of the complexity of requirements management in construction projects", Engineering, Construction and Architectural Management, 21( )5, 505 - 531

Bradley, G. (2010), Benefit Realisation Management: A Practical Guide to Achieving Benefits Through Change, 2nd ed., Gower, Farnham.

Brady, T. and Davies, A. (2010), "From hero to hubris - reconsidering the project management of Heathrow’s Terminal 5”, International Journal of Project Management, Vol. 28 No. 2, pp. 151-157.

Breese, R. (2012), “Benefits realisation management: panacea or false dawn?”, International Journal of Project Management, Vol. 30 No. 3, pp. 341-351.

Brennan, K. (Ed.) (2009), A Guide To The Business Analysis Body Of Knowledge (BABOKs Guide) Version 2.0, International Institute of Business Analysis, Toronto.

British Standards Institution (2000), BS EN 12973:2000 - Value Management, BSI, London.

Bryman, A. (2008), Social Research Methods, 3rd ed., Oxford University Press, Oxford.

Charmaz, K. (2006), Constructing Grounded Theory: A Practical Guide Through Qualitative Analysis, Sage, London.

Charoenngam, C., Coquinco, S.T. and Hadikusumo, B.H.W. (2003), “Web based application for managing change orders in construction projects”, Construction Innovation, Vol. 3 No. 4, pp. 197215.

Chartered Institute of Building (2011), Guide to Good Practice in the Management of Time in Complex Project, Wiley-Blackwell, Chichester.

Creswell, J.W. (2009), Research Design: Qualitative, Quantitative, and Mixed Methods Approaches, 3rd ed., Sage, Thousand Oaks, CA.

Davis, A.M. and Zweig, S. (2000), “Requirements management made easy”, PM Network, Vol. 14 No. 12, pp. 61-63.

Egan, J. (1998), Rethinking Construction, HMSO, London.

Fernie, S., Green, S.D. and Weller, S.J. (2003), "Dilettantes, discipline and discourse: requirements management for construction”, Engineering, Construction and Architectural Management, Vol. 10 No. 5, pp. 354-367.

Gallaher, M.P., O’Connor, A.C., Dettbarn, J.L. and Gilday, L.T. (2004), Cost Analysis of Inadequate Interoperability in the US Capital Facilities Industry, National Institute of Standards and Technology, Gaithersburg, MD.

Gibson, W.J. and Brown, A. (2009), Working with Qualitative Data, Sage, London.

Gray, D.E. (2009), Doing Research in the Real World, 2nd ed., Sage, London.

Green, S., Newcombe, R., Fernie, S. and Weller, S. (2004), Learning Across Business Sectors: Knowledge Sharing Between Aerospace and Construction, University of Reading, Reading.

Griffith, A. (2011), Integrated Management Systems for Construction, Prentice Hall, London.

Halbleib, H. (2004), “Requirements management”, Information Systems Management, Vol. 21 No. 1, pp. 8-14.

Hegazy, T., Zaneldin, E. and Grierson, D. (2001), "Improving design coordination for building projects. I: information model”, Journal of Construction Engineering and Management, Vol. 127 No. 4, pp. 322-329.

Jallow, A.K. (2011), “Integrated lifecycle requirements information management (eRIM) in construction projects”, unpublished PhD thesis, Loughborough University, Loughborough, February. 
Jallow, A.K., Demian, P., Baldwin, A. and Anumba, C. (2008), "Life cycle approach to requirements information management in construction projects: state-of-the-art and future trends”, in Dainty, A. (Ed.), Proceedings of the 24th Annual ARCOM Conference, September 1-3, Association of Researchers in Construction Management, Cardiff, pp. 769-778.

Jallow, A.K., Demian, P., Baldwin, A. and Anumba, C. (2010), "Development of an innovative framework for clients' requirements information management in construction projects”, in Anumba et al. (Eds), Proceedings of the 6th International Conference on Innovation in Architecture, Engineering and Construction (AEC), June 9-11, Penn State University, University Park, pp. 298301.

Kamara, J.M. and Anumba, C.J. (2000), “Client requirements processing for concurrent life-cycle design and construction”, Concurrent Engineering: Research and Applications, Vol. 8 No. 2, pp. 74-88.

Kamara, J.M., Anumba, C.J. and Evbuomwan, N.F.O. (2002), Capturing Client Requirements in Construction Projects, Thomas Telford Ltd, London.

Kiviniemi, A. (2005), Requirements Management Interface to Building Product Models, CIFE, Stanford University, Stanford, CA.

Kiviniemi, A., Fischer, M., Bazjanac, V. and Paulson, B. (2004), PREMISS -Requirements Management Interface to Building Product Models: Problem Definition and Research Issue, CIFE, Stanford University, Stanford, CA.

Kliniotou, M. (2004), “Identifying, measuring and monitoring value during project development”, European Journal of Engineering Education, Vol. 29 No. 3, pp. 367-376.

Latham, M. (1994), Constructing the Team, HMSO, London.

Li, Y., Yang, M., Klein, G. and Chen, H. (2011), “The role of team problem solving competency in information system development projects”, International Journal of Project Management, Vol. 29 No. 7, pp. 911-922.

Maciaszek, L.A. (2007), Requirements Analysis and System Design, 3rd ed., Addison-Wesley, Harlow.

Mahaney, R.C. and Lederer, A.L. (2010), “The role of monitoring and shirking in information systems project management”, International Journal of Project Management, Vol. 28 No. 1, pp. 14-25.

Moser, T., Winkler, D., Heindl, M. and Biffl, S. (2011), "Requirements management with semantic technology: an empirical study on automated requirements categorization and conflict analysis”, in Mouratidis, H. and Rolland, C. (Eds), Proceedings of the 23rd International Conference on Advanced Information Systems Engineering, June 20-24, Springer-Verlag, London, pp. 3-17.

Nuseibeh, B. and Easterbrook, S. (2000), "Requirements engineering: a roadmap”, Proceedings of the IEEE International Conference on Software Engineering, ACM New York, NY, pp. 35-46.

Office of Government Commerce (2005), Common Causes of Project Failure, OGC, London.

Office of Government Commerce (2009a), “Overview of managing successful programmes (MSP)”, July, available at:

www.ogc.gov.uk/delivery_lifecycle_overview_of_managing_successful_programmes_msp_.asp (accessed May 15, 2011).

Office of Government Commerce (2009b), Requirements Management, 13 July, available at: www.ogc.gov.uk/delivery_lifecycle_requirements_management.asp (accessed January 20, 2008). 
AK Jallow , P Demian , AN Baldwin , C Anumba , (2014) "An empirical study of the complexity of requirements management in construction projects", Engineering, Construction and Architectural Management, 21( )5, 505 - 531

Ozkaya, I. and Akin, O * (2007), “Tool support for computer-aided requirement traceability in architectural design: the case of designtrack", Automation in Construction, Vol. 16 No. 5, pp. 674684.

Pena, W.M. and Parshall, S.A. (2001), Problem Seeking: An Architectural Programming Primer, 4th ed., John Wiley \& Sons, New York, Chichester.

Potts, K. (2008), “Change in the quantity surveying profession”, in Smyth, H. and Pryke, S. (Eds), Collaborative Relationships in Construction: Developing Frameworks and Networks, WileyBlackwell, Oxford, pp. 42-58.

Rezgui, Y., Zarli, A. and Hopfe, C.J. (2009), "Editorial - building information modelling applications, challenges and future directions”, Journal of Information Technology in Construction, Vol. 14 (Special Issue), pp. 613-616.

Robertson, S. and Robertson, J. (2006), Mastering the Requirements Process, 2nd ed., Addison-Wesley, London.

Robson, C. (2002), Real World Research: A Resource for Social Scientists and Practitioner-Researchers, 2nd ed., Blackwell, Oxford.

Rockwood, G.F. (1993), “Edgar Schein's process versus content consultation models”, Journal of Counseling \& Development, Vol. 71 No. 6, pp. 636-638.

Roy, R., Kerr, C.I.V., Sackett, P.J. and Corbett, J. (2005), “Design requirements management using an ontological framework”, CIRP Annals - Manufacturing Technology, Vol. 54 No. 1, pp. 109-112.

Royal Institute of British Architects (RIBA) (2007), Outline Plan of Work, RIBA, London.

Royal Institute of British Architects (2012), “RIBA plan of work 2013: consultation document”, available at: www.architecture.com/Files/RIBAProfessionalServices/Practice/FrontlineLetters/RIBAPlanofWor k2013ConsultationDocument.pdf (accessed January 10, 2013).

Sapountzis, S., Yates, K., Kagioglou, M. and Aouad, G. (2009), "Realising benefits in primary healthcare infrastructures”, Facilities, Vol. 27 Nos 3/4, pp. 74-87.

Schein, E.H. (1978), “The role of the consultant: content expert or process facilitator”, The Personnel and Guidance Journal, Vol. 56 No. 7, pp. 339-344.

Sinclair, D. (Ed.) (2012), BIM Overlay to the RIBA Outline Plan of Work, RIBA, London.

Sinha, V., Sengupta, B. and Chandra, S. (2006), "Enabling collaboration in distributed requirements management”, IEEE Software, Vol. 23 No. 5, pp. 52-61.

Sun, M. and Howard, R. (2004), Understanding IT in Construction, E\&F N Spon, London.

Swenden, W. (2006), Federalism and Regionalism in Western Europe: A Comparative and Thematic Analysis, Palgrave Macmillan, Basingstoke.

Tesch, D., Kloppenborg, T.J. and Frolick, M.N. (2007), "It project risk factors: the project management professionals perspective”, Journal of Computer Information Systems, Vol. 47 No. 4, pp. 61-69.

Vasilescu, A., Dima, A.M. and Vasilache, S. (2009), "Credit analysis policies in construction project finance”, Management \& Marketing, Vol. 4 No. 2, pp. 79-94.

Wiegers, K.E. and McKinsey, S. (2005), "Requirements management: the proven way to accelerate development”, WP900_001_0505, Serena Software Inc., available at: www.serena.com/docs/repository/products/rm/wp900-001-0505.pdf (accessed August 10, 2012). 
AK Jallow , P Demian , AN Baldwin , C Anumba , (2014) "An empirical study of the complexity of requirements management in construction projects", Engineering, Construction and Architectural Management, 21( )5, 505 - 531

Worthington, J. (2000), “The briefing and design process”, Overhead Material Seminar, Chalmers University of Technology, Go"teborg, February 2.

Yu, A.T.W., Shen, G.Q.P. and Chan, E.H.W. (2010), “Managing employers’ requirements in construction industry: experiences and challenges”, Facilities, Vol. 28 Nos 7/8, pp. 371-382.

Further Reading

Demian, P. and Fruchter, R. (2006), “An ethnographic study of design knowledge reuse in the architecture, engineering, and construction industry”, Research in Engineering Design, Vol. 16 No. 4, pp. 184-195.

Fellows, R. and Liu, A. (2008), Research Methods for Construction, 3rd ed., Wiley-Blackwell, Oxford.

Lee, W.B., Cheung, C.F., Lau, H.C.W. and Choy, K.L. (2003), "Development of a web-based enterprise collaborative platform for networked enterprises”, Business Process Management Journal, Vol. 9 No. 1, pp. 46-59.

Stewart, R.A. (2008), “A framework for the life cycle management of information technology projects: project IT”, International Journal of Project Management, Vol. 26 No. 2, pp. 203-212. 